\title{
ENQUANTO SE ESPERA PELAS DIRETRIZES E BASES
}

\author{
A. Almeida Júnior \\ Da Universidade de São Paulo
}

\begin{abstract}
Desde que entraram a funcionar os dois Cursos Jurídicos e as duas Academias Médico-Cirúrgicas do Império, o comentário ao ensino superior brasileiro se tem situado entre dois polos: o do louvor mais ou menos saudosista do passado e o da esperança exageradamente ingênua na próxima reforma. 0 presente é mau: quanto a isto não há dúvida. Mas atraz, no sistema escolar de ontem, que a bruma das reminiscências engrandece, estavam a seriedade e a perfeição, a sabedoria austera dos mestres e a ânsia de aprender dos discípulos, - dêsses discípulos que depois realmente se fizeram os pró-homens da nacionalidade; estava, enfim, como dissemos há tempos, o paraíso perdido do ensino superior. Por outro lado, em nossa frente, abrigando-se em estado potencial no texto de algum projeto legislativo, aprestam-se para germinar as sementes de nova fase de glória das escolas, - a Terra da Promissão da educação brasileira. Angustiados, assim, entre o Eden de óntem e a Canaã do futuro, temos vivido, desde 1827 até hoje, a gastar o nosso tempo em duas coisas pouco produtivas: - recordar e esperar.

Já examinei numa outra oportunidade, em referência ao problema do ensino superior, êsse conhecido vício de refração da psicologia humana, que consiste em avantajar imerecidamente o passado à custa do presente. Pretendo agora analisar o vício oposto, ou seja o de confiar demasiado no futuro, nas virtudes das leis reformadoras e supor que estas leis, só por si, poderão corrigir tôdas as insuficiências das instituições.
\end{abstract}


Conservamos neste particular um pouco de inocência do homem primitivo que se refugia na inatividade porque acredita no poder místico das palavras, a cuja fôrça entrega a realização dos seus mais caros desígnios.

Vimos pedindo ao legislativo nacional, desde a época do Sr. D. Pedro I, que pronuncie esta ou aquela fórmula cabalística, tida no momento como eficaz contra as doenças do nosso ensino superior.

A fórmula tem variado: "Ensino oficial", "ensino livre", "fiscalização", "uniformidade", "descentralização", "autonomia", "universidade", "federalização", "plano nacional", "diretrizes e bases..." A de hoje contradiz a de óntem e será certamente desmentida pela de amanhã. Pouco importa. Com a solenidade e a lentidão peculiares aos seus ritos, o poder legislativo acaba por proferir a palavra mágica que todos reclamam. Mas o ensino superior brasileiro, no que êle tem de básico e essencial; o ensino tal como funciona nas salas, anfiteatros e laboratórios das faculdades; o ensino como forma de transmissão de cultura e de ampliação de conhecimentos; como estímulo às aptidões da juventude; como instrumento de compreensão entre os homens e de criação da riqueza do País, - êsse tem resistido à exortação das fórmulas legais, tem-se negado a acelerar a lentidão exasperante do seu rítmo progressivo em uma inércia que seria para desesperar se muitas vezes essa mesma inércia não cumprisse a função defensiva de parachoques contra a desagregação.

Selecionemos alguns exemplos em favor da nossa tese.

0 ensino livre foi a primeira fórmula de grande estilo que se apregoou no Brasil independente, como apta a salvar a educação superior da decadência a que chegara, menos de vinte anos após a criação das quatro Academias. Sim: da "decadência", — pois já a êsse tempo a expressão era corriqueira na bôca dos comentadores do nosso incipiente aparelho educacional. 0 conceito de ensino livre, que em sua plenitude significa a licença concedida aos particulares para fundar e manter escolas sem nenhuma regulamentação ou fiscalização oficial, proviera, 
na Europa, de reivindicações políticas e religiosas. "Todo homem possui o direito de ensinar o que sabe e, até, o que não sabe", - proclamara Mirabeau na Assembléia Nacional revolucionária. O princípio fôra em si mesmo condenado pelo "Sylabus" e, posteriormente, por Leão XIII. A Igreja (disse o padre Taparelli em 1841) "é a depositária da verdade; só ela é infalível; só ela deve educar. "Impedida, contudo, de fazê-lo em caráter privativo, ou forçada a fazê-lo sob a vigilância do Estado, reagira pelo grito de guerra do ensino livre, tão ao sabor dos pródromos do liberalismo político, que condenava qualquer intervenção do Estado nos domínios da educação.

No Brasil Imperial, a campanha do ensino livre se fez muito mais por convicção política do que por estratégia do clero, aliás profundamente liberal. Os líderes nacionais de então não haviam notado (como advertiu na Câmara Joaquim Nabuco) que, em matéria de ensino, os partidos avançados europeus, tendo reconhecido o êrro do abstencionismo, estavam convertidos à tese do ensino oficial, a fim de que o Estado democrático fôsse dado criar e pôr em atividade, sem distinção nem privilégios, tôdas as condições necessárias para o integral desenvolvimento do indivíduo. Continuava-se ainda entre nós, nas Congregações docentes como no Parlamento, a transferir para 0 plano da cultura do espírito a teoria aplicada à produção econômica: "laissez faire, laissez aller"... Sobram homens cultos no País (afirmava-se enfáticamente), que poderão ensinar se a lei não o proibir. A ânsia de aprender, característica da nossa mocidade, incentivará a proliferação de escolas. A sagacidade do pai de família saberá discernir entre os bons e os maus educadores. Os próprios estudantes fugirão dos mestres incapazes para acorrerem em massa às aulas dos que ensinarem...

Pinta-se com tintas escuras a paisagem do ensino superior brasileiro: instalações péssimas, má escolha dos catedráticos, professôres desidiosos, alunos sem base propedêutica, sem interêsse e sem aplicação; pais que pedem para os filhos, não ensino, mas diplomas; excesso de indulgência nas aprovações; fraude nos exames, a ignorância ao fim do curso. Contra tudo isso, contra 'esta série de sintomas - infelizmente comprovados, 
- da generalizada debilidade cultural da população, indica-se como panaceia capaz de tudo endireitar da noite para o dia, o ensino livre, um ensino livre avassalador, que co-existiria com as escolas do Estado até que estas, enfim, se fechassem por desprezadas e inúteis.

Mesmo sôbre a sonolenta grei do professorado oficial, enquanto êste não desaparecesse, seriam benéficos os eflúvios emanados do magistério livre. Era simples o argumento do deputado Cunha Leitão. Para que os lentes das quatro Academias entrem a trabalhar, dois recursos se nos oferecem: ou aumentar-lhes os vencimentos (que o ordenado dêles é realmente mesquinho), ou chamá-los a brios pela emulação. Impossível, como se sabe, a primeira terapêutica, use-se a segunda, - a competição pelo ensino livre. Por que êste (observa Alves de Melo, professor na Bahia), estabelecendo a concorrência e, conseguintemente, criando o estímulo e a emulação" é o elemento de vida do professorado oficial".

Até aqui a teoria, que podemos condensar em três itens: falsos pressupostos de psicologia, tanto dos moços como dos velhos; desconhecimento da realidade brasileira; concepção errônea das funções do Estado em matéria de educação. As consequências o demonstraram. $O$ ensino de medicina teve ensêjo de ser livre no País, sem nenhuma fiscalização, desde a lei de 3 de outubro de 1832. Teve igualmente a mesma oportunidade 0 ensino de qualquer profissão liberal desde a reforma de Leôncio de Carvalho, em 1879. Todavia, o ambiente cultural da época, imaturo para incentivar a criação de cursos particulares de grau superior, ou para abastecê-los de bons professôres (pois que os bons professôres escasseavam até para o ensino oficial), não reagiu como esperavam os pregoeiros da reforma. Nem em São Paulo, nem no Recife vieram à tona professôres livres de direito ou medicina; e os cursos livres do Rio e da Bahia, que foram pouquíssimos, ou logo se fecharam ou tiveram frequência diminuta. Demais, onde quer que existissem, deveriam os seus alunos prestar exames perante as escolas oficiais; e essa condição atemorizadora - o exame de Estado - era mais do que suficiente para esfriar o entusiasmo da juventude. Só bem 
depois, nos primórdios da República, e com a reforma de Benjamin Constant, foi que as faculdades livres, recebendo em troca da fiscalização a prerrogativa de conferir graus profissionais, conseguiram enfim grangear clientela.

Mas o climax do ensino livre estava ainda por vir, e veio em 1911. Ao assumir o govêrno da República, havia o Marechal Hermes da Fonseca dito horrores do ensino superior: "o mercantilismo chegou ao auge"; "as escolas superiores são tomadas de assalto por uma multidão de incapazes"; desceu o ensino a tal descrédito que, "ou se faz a sua reforma radical, ou preferível será aboli-lo de uma vez".

Aparece daí a reforma Rivadávia. Vem envolvida na roupagem compósita do liberalismo político e do positivismo filosófico, e arrasta o Estado, francamente, para o caminho da abstenção. Não se fiscalizam as escolas; não há exames oficiais; entra em eclipse a prova de capacidade para o exercício profissional.

Ensino quem quiser, onde quiser, como quiser. Suprimam-se os diplomas, - "miragem perturbadora da burguezia fátua". Conceda-se autonomia ampla, - administrativa e didática, - aos institutos oficiais.

Durou pouco a experiência, - um quatriênio apenas. Mas êsse breve período bastou para evidenciar que, em lugar de curar os males denunciados pelo Presidente da República, a audaciosa inovação do seu Ministro da Justiça os agravara. Fôra "varrido por um tufão" o ensino secundário, - disse a Comissão de Instrução Pública da Câmara, pois não o estimulavam ao esfôrço e à seriedade os sumaríssimos exames vestibulares das Academias. Improvisaram-se Universidades; brotaram escolas superiores como cogumelos; proliferou o ensino universitário por correspondência; fez-se dos títulos acadêmicos (que continuavam a valer, a despeito da lei) objeto do mais vergonhoso comércio; tanto que "diplomas de médicos, advogados ou engenheiros, diplomas de $60 \$ 000$, como vieram a ser conhecidos (porque era êsse, realmente, o seu preço) - inundaram durante dois ou três decênios o mercado profissional do País e das Repúblicas sul-americanas. 
Falhara, portanto, no Brasil, o ensino livre com que havia sonhado o liberalismo educacional dos homens do segundo Império ou a ingenuidade filosófica do Ministro de 1911. Em nenhuma das duas grandes tentativas, é verdade, causara êle, só por si, todos os males de que o acusaram e ainda o acusam os seus críticos. Mas de qualquer forma, nem produziu os benefícios que dêle esperavam os reformadores, nem tampouco se isentou da responsabilidade de muitos e danosos efeitos com que num e noutro caso prejudicou o nosso ensino superior.

Outra fórmula salvadora, louvada em prosa e verso e pela qual se batem quase todos os mestres da atualidade, é a autonomia dos institutos de ensino superior. Reclamou-se a Joaquim Nabuco ao criticar a reforma de Leôncio de Carvalho: "Conceda o nobre Ministro autonomia às faculdades". "Emancipe da tutela do Govêrno o ensino do Estado". De 1903 em diante, a propósito da criação de universidades, alça-se aí da mais a voz dos autonomistas, que ganha em volume logo depois da criação, em 1920, da Universidade do Rio de Janeiro, para culminar, decreto-lei n. 8.393, de 17 de dezembro de 1945, com que foi concedida autonomia administrativa, financeira, didática e disciplinar à Universidade do Brasil. Nesse mesmo ano, em memorável Congresso, a Associação Brasileira de Educação reclamava: "o regime de autonomia, inegável condição para a vida normal dessas instituições de ensino, pesquisa e divulgação cultural, já experimentado com êxito no País, deverá ser aplicado a tôdas as universidades brasileiras".

Vejamos, porém, o que nos diz a experiência nacional. Era ampla a autonomia das duas escolas médicas imperiais, até 1854, sem que de semelhante regime houvessem elas tirado qualquer benefício especial para o ensino. Bastante autônomo, do ponto de vista didático, foi o sistema instituido em 1915 por Carlos Maximiliano, inclusive naquilo que o Sr. Gustavo Capanema considera, hoje, "desmedido arbítrio", capaz, na opinião de sua Excia., de pôr em risco a unidade nacional, - ou seja o poder conferido a cada congregação, pelo projeto de diretrizes e bases, de organizar o seu currículo. A êsse propósito o Ministro Maximiliano recordou, no aviso de 15 de julho de 1918, que 
a lei de então (como o projeto de agora de Clemente Mariani) nem sequer designava as matérias de cada curso superior, pois deixava às congregações a iniciativa da escolha e seriação, e ao Conselho Superior de Ensino o direito de aprovar ou regeitar o plano proposto. Que resultados benéficos provieram dêsse período? Se algum ocorreu, não se tornou evidente, aos olhos do Govêrno, pois em 1923 o Ministro João Luiz Alves volta a falar em "decadência incontestável do ensino superior", e propõe, como remédio, primeiro, a "seleção rigorosa dos professôres" - dando desta forma a entender que o mal estava na qualidade dos mestres; e, segundo", a obrigação, por parte dêstes, de exercerem efetivamente o magistério", - fazendo acreditar, assim, que aqueles mestres o que não queriam era trabalhar.

A experiência mais avançada em matéria de autonomia, anterior ao atual regime universitário, foi sem dúvida a da reforma Rivadávia, já conhecida por sua fertilidade com decepções no tocante ao ensino livre. Os institutos oficiais passaram a corporações autônomas, tanto do ponto de vista didático como administrativo, e as escolas que viessem a prescindir da subvenção do govêrno ficariam isentas de tôda e qualquer dependência ou fiscalização oficial.

Souberam por ventura as congregações autônomas servir-se das franquias outorgadas pela lei, para ampliar ou aperfeiçoar o ensino? Para torná-lo mais eficaz? Para encaminhar em favor da educação da juventude e da formação dos futuros profissionais os recursos de que dispunham? Responda por nós o Ministro Carlos Maximiliano, ao relatar o que encontrou:

Esta Academia distribuiu entre os lentes as taxas outrora recolhidas ao Tesouro, e não mais comprou um aparelho, não consertou um banco, não reparou uma parede; aquela desviou as verbas destinadas à maternidade anexa, desibaratando-a em obras suntuárias. Em um instituto o diretor comparecia para almoçar uma ou duas vezes por mês; e lá encontraram o projeto, encomendado a um arquiteto, de uma casa para o secretário, de outra para o sub-secretário, e de terceira, para pessoa inti- 
mamente ligada a um dêsses dois funcionários", - tudo isto (continua o Ministro), num estabelecimento cujas rendas decresceram de $66 \%$ em quatro anos". "Professor de cadeira estudada em vários anos reprovava todos os examinandos do primeiro, a fim de não ter alunos no segundo; dois outros não davam aula e pagavam duzentos mil réis a estudantes para os substituirem. Assistentes pediam ao professor para os declarar incompatíveis com êle, porque ficavam em disponibilidade, percebendo vencimentos sem prestar serviços. Houve lentes que deram dez aulas por ano. Pomposos e vastos programas encantavam o visitante; porém não eram ensinados em aula senão os pontos dos intermináveis prolegómenos". "Uma exceção é conhecida (conclui o Ministro), porém uma só; os professôres da Faculdade de Direito de São Paulo abriram mão das taxas de exames, e com o seu produto substituiram o mobiliário da gloriosa Academia".

Sou um crente nas virtudes da autonomia universitária, pois nele vejo não só uma fôrça vivificadora das iniciativas didáticas e do aperfeiçoamento do ensino, como ainda a expressão da democracia dentro das escolas. Contudo, diante dos resultados que acabamos de apontar, indicativos de que a emancipação das congregações se caracterisou no passado por abusos detestáveis, como supor que foi a falta de autonomia que tolheu a expansão dos nossos institutos de grau superior?

Os ensinamentos dêsse passado devem pôr-nos de sobreaviso. Instituamos a autonomia, mas tomemos precauções para que à sua sombra os órgãos acadêmicos não decurem o ensino; não malbaratem o dinheiro do povo distribuindo-os ao sabor das amizades, da fantasia ou dos caprichos de seus membros; não permitam que os professôres se eximam de prestar contas até mesmo ao tesoureiro da casa, da negligência com que exercem as suas funções, nas quais lesam ao mesmo tempo a preparação dos futuros profissionais e a formação moral da juventude. Tenha-se presente que autonomia não significa liberdade sem contrôle, devendo ela, ao contrário, ser circunscrita por limites muitos claros e, além disto, fiscalizada em seu exercício por um poder superior, extranho à instituição, e que represente 
os interêsses da comunidade sôbre que recai o onus de pagar as despesas da casa. Entendemos ainda que, não constituindo a autonomia um fim em si, mas apenas uma condição para melhorar e dignificar o trabalho docente, preferível será, enquanto não puder produzir tais resultados, que a eliminemos das leis escolares, até que os seus beneficiários se alcem à altura de merecê-la.

Mas passemos a outro assunto. Não parece justo que cuidemos de fórmulas milagrosas sem aludirmos aquela que mais inflamou a juventude do último quartel do século passado. Veio no bojo da reforma Leôncio de Carvalho e teve por isso, entre os estudantes, o rótulo inadequado, mas habilíssimo, de "ensino livre", tão grato à sensibilidade liberal do segundo Império. Sua essência resumia-se neste parágrafo da lei, gravado em letras de ouro no coração da mocidade acadêmica: "não serão marcadas faltas aos alunos, nem serão êles chamados a lições e sabatinas". Dispensa de vir as aulas, do comêço ao fim do ano! Bôca fechada às perguntas do mestre, - que isto de mostrar que se estudou a lição é quebra da dignidade... Ua maravilha aos olhos imprevidentes da adolescência!

Com evidente falseamento dos fatos, alegava-se que era assim que se fazia na Europa e nos Estados Unidos. Demais, aplicava-se ao caso a discutível psicologia a que nos referimos há pouco: os moços o que querem é aprender, os lentes o que pretendem são as palmas do auditório. Dêmos liberdade aos moços, e todos acorrerão às aulas dos bons professôres, para aplaudí-los, abandonando os outros, os que não ensinam, os professôres "morfina", na expressão do deputado Brício Filho. E' possível que um ou outro rapaz se prevaleça destas franquias para não ir às aulas e nem sequer abrir os livros. Serão raríssimos êsses madraços, e contra êles (argumenta o reformador) se erguerá no fim do ano a barreira dos exames. Sim! Exames inexoráveis : - eis o segrêdo do sistema. Ensinar bem êsses velhos lentes não ensinam; mas examinar é com êles.

Tais foram os pressupostos do regime de frequência livre instituido em 1879; a incapacidade docente dos professôres 
oficiais: a inata curiosidade intelectual da juventude, o poder estimulante do comparecimento dos alunos sôbre a assiduidade e a didática dos lentes; a excelência dos exames finais como incentivo ao estudo durante o ano e como instrumento de avaliação da capacidade dos alunos.

Fez-se a experiência, melancólica experiência, que durou dezesseis anos nos cursos jurídicos e cinco anos mais nos outros cursos superiores. Quais os resultados? Não há nenhum exagêro em dizer-se que o regime de frequência livre, de 1879, foi um dos piores fiascos das nossas reformas educacionais. Os moços se dispersaram nas suas províncias, nos engenhos, nas fazendas, nos empregos, nas viagens, - cessando quase por completo aquêle convívio acadêmico do período anterior, tão valioso para a cultura geral da elite juvenil brasileira e para 0 fortalecimento da unidade nacional.

As Academias se despovoaram, dias houve em que não se deu aula por ausência total de estudantes. Quanto aos lentes, - êsses permaneceram impassíveis como granito ao estímulo da imaginária concorrência, e indiferentes à deserção dos alunos: os bons continuaram bons, os maus tornaram-se piores. E o baluarte dos exames? A posição chave no sistema defensivo da reforma? Rendeu-se com armas e bagagens (como sempre se rendera) à grita dos estudantes, à pressão do meio social, ao compadresco, às concessões dos Ministros e da Câmara. Nunca houve exames tão ruins, - declaram os relatórios da época; mas a taxa de reprovações se manteve modestíssima.

As enormes facilidades de formatura que decorreram dêsse estado de coisas, permitiram que em quatro, em três e até em dois anos se diplomassem numerosos médicos e centenas de bachareis em direito. Médicos "elétricos", bachareis "elétricos" - repetia-se nas ruas e nos jornais. Em 1894 o deputado Adolfo Gordo, da Comissão de Instrução Pública, declarava na tribuna da Câmara: "Podemos dizer que não temos mais ensino de direito." " $E$ ' o naufrágio do ensino superior!" - completava, desalentado, Martins Júnior. Reconhecida através destas e outras manifestações a falência do regime, a frequência livre 
desaparecia, em 1896, dos Estatutos das faculdades de direito, e, em 1901, dos Regulamentos das outras faculdades. E o próprio Leôncio de Carvalho, pai oficial da instituição, admitia publicamente, em 1908, que a sua terapêutica não era a mais indicada para despertar as Academias brasileiras do marasmo em que jaziam.

Decepcionados pelo ensino livre, decepcionados pela autonomia sem contrôle e pela liberdade de frequência, - ou seja por três das muitas fórmulas salvadoras do ensino superior, justo é que perguntemos agora: - $\mathrm{E}$ as contra-reformas? Produziram, acaso, algum milagre?

Em contraste com as faculdades livres, que só principiaram a funcionar com o advento da República, tivemos desde 1828 as faculdades oficiais, hoje disseminadas por todo o País. Foram defeituosíssimas (já o dissemos) as quatro Academias imperiais, sob todos os aspectos inclusive pelas desatenções com que tratavam os seus próprios Estatutos.

Delas pôde afirmar Ruy Barbosa em 1881: "Os tetos das nossas faculdades cobrem abusos inauditos, escândalos tradicionais, quebras intoleráveis da lei, perpetuadas pela incúria de uns e legitimadas pelo silêncio de outros". Melhorou o sistema neste século, moderadamente, não podendo entretanto incluir-se nesse juizo optimista, por carência de dados objetivos, as faculdades últimamente colhidas na rêde política das federalizações, a respeito de alguma das quais é lícito fazer desde já reservas muito sérias. Mas devemos declarar sem hesitação que só em pequena parte, e isto mesmo por via indireta, o fato de pertencer a escola ao Estado pode influir favoravelmente sôbre a sua eficiência. Porque realmente o que importa é o aumento de recursos financeiros, é a elevação cultural do ambiente em que funciona, é sobretudo a melhor compreensão dos respectivos deveres por parte de seus dirigentes e de seu professorado. Existem faculdades, livres tão boas quanto as melhores mantidas pelo poder público e há, de outra parte, escolas superiores oficiais que não ficarão deslocadas entre as piores do sistema privado. 0 confronto, aliás, não é novo, pois já o fizera 
Dunshee de Abranches em 1903, no seu relatório ao Ministro da Justiça. Instáveis eram então os professôres, tanto nas escolas oficiais como nas livres; pouco assíduos nestas e naquelas; criminosamente benévolos nas de uma e outra categoria.

Crêmos, pois, - e isto vai dito entre parênteses, - que se viermos a adotar o exame de Estado (contra o qual, aliás, já apresentei diversas objeções), deverão, por justiça, submeter-se a êle, indistintamente, todos os candidatos às profissões de grau universitário, quer provenham das escolas livres, quer das escolas oficiais.

Mostraremos os efeitos da irrestrita liberdade de ensino e da desvairada autonomia, ensejadas pela reforma Rivadávia. A título de contraste vejamos o polo oposto, em que se situa a legislação federal minudente de nossos dias, reguladora das condições de abertura das faculdades livres ou estaduais, e disciplinadora da estrutura e funcionamento dos institutos de ensino superior em geral.

Aqui, sem dúvida, ressalvados os inegáveis e múltiplos excessos, a vantagem se coloca do lado da legislação atual. Infelizmente, porém, estamos sob muitos aspectos bastante longe da legalidade. Atendido um certo mínimo, quase sempre bem modesto, e satisfeitas as exigências formais, cada estabelecimento de ensino não é bem o que a lei determina, não é o que está no espírito da lei, mas aquilo que consulta aos propósitos algumas vezes indefensáveis dos mantenedores do instituto, ou então aquilo que resulta da moralidade dos seus professôres.

Citemos dois exemplos. Em louvável progressão no rigor com que investiga e interpreta as condições legais de autorização para novos cursos, o Conselho Nacional de Educação se tem fixado principalmente neste problema básico, que é o da idoneidade moral e técnica dos professôres propostos. Trata-se, é claro, de professôres interinos, pois que o corpo docente efetivo será recrutado depois, mediante concurso.

Mas os interinos inaugurais permanecem, de regra, anos e anos na regência das cátedras, ora porque 0 instituto não se 
apressa em realizar os concursos, ora porque as vantagens do cargo ou da localidade não tentam os elementos capazes. Na espectativa, portanto, de que o corpo docente interino vai lançar no mercado profissional turmas sucessivas de médicos, juristas, engenheiros e outros titulares, não é prudente que, mesmo na fase inicial da vida da faculdade, entreguemos o seu ensino a pessoas que não demonstrem préviamente, de forma insofismável, um mínimo de competência. Foi por isso que propús ao Conselho, em 1950, a seguinte fórmula definidora dêsse mínimo: $10^{\circ}$ ) diploma de curso superior onde o candidato haja estudado a disciplina que pretende lecionar; $2 .^{\circ}$ ) prova de um comêço de especialização nessa disciplina. Entendí necessário êste segundo requisito porque, como é óbvio, a simples aprovação nos exames acadêmicos não basta para o exercício do magis tério. Todos sabemos perfeitamente que não é qualquer bacharel em direito que pode ensinar, em grau superior, direito romano, ou filosofia do direito, ou teoria geral do Estado; nem é qualquer médico que está em condições de lecionar indiferentemente clínica módica ou clínica cirúrgica, psiquiatria ou anatomia descritiva.

A primeira reação a essa norma, que a defesa do interêsse público e da cultura inspirou, foi de indignada repulsa: estávamos nós a dificultar a expansão do ensino superior no País; estávamos a impedir que as cidades longínquas tivessem a sua faculdade superior. Depois, veio coisa pior do que a repulsa: - veio a simulação, que já existia e que agora se acentuou. Para impressionar os responsáveis federais e o próprio público, a entidade mantenedora coleciona uma dezena de nomes mais ou menos prestigiosos do magistério oficial; enfeita a lista com um governador de Estado, com dois ou três deputados, um senador, um diplomata, um jornalista de pról, não raro residentes a centenas de quilômetros do instituto, e está organizada a sua congregação. Congregação de fachada - podemos dizer, pois que em maioria êstes homens ilustres não pretendem lecionar, nem podem lecionar na nova faculdade. Dão apenas o nome, como é de uso fazerem os farmacêuticos, ficando a obrigação das cátedras confiada a pequeno número de rapazes de 
boa vontade. A lei está certa; entretanto, porque claudicam os que devem respeitá-la, e porque o primeiro gesto dos responsáveis está eivado de insinceridade, a situação tende a retroceder para os tempos da reforma Rivadávia.

Outro exemplo expressivo é o da limitação da matrícula, cujo princípio figura na legislação federal. São evidentes, como se sabe, as vantagens que decorrem do preceito, tanto para a eficiência do ensino como para a sua moralidade. Está em primeiro lugar o imperativo, referido na lei, de acomodar-se a matrícula à amplitude e aos demais recursos das instalações. ótimas escolas médicas brasileiras, embora dotadas de salas e laboratórios espaçosos e de excelentes serviços hospitalares tem-se negado a ultrapassar de cem alunos, ou até de oitenta, o total de cada série. Vem em segundo lugar a importância, que cada vez mais se reconhece, do contacto pessoal entre professôres e alunos. Êsse contacto não interessa apenas para a fiscalização material da frequência e para a melhor avaliação da capacidade do estudante: vale também como oportunidade de estímulo e orientação. $\mathrm{E}$ é óbvio que, com o aैumento desmedido da matrícula, o contacto pessoal vai diminuindo, o aluno vai-se tornando um anónimo para os seus mestres. Releva notar igualmente, como consequência indireta - e benéfica - da limitação, a competição criada entre os candidatos para obterem os primeiros lugares. As duas Escolas Médicas a a Escola Politécnica da Capital paulista (para citarmos exemplos, que nos são familiares, com a inflexibilidade de seus limites de matrícula, estão exercendo naquele Estado uma influência visível em favor do estudo das disciplinas exigidas para ingresso na primeira série. Importa assinalar, enfim, que a ausência de limitação, ou a facilidade com que se amplia a limitação pre-existente, são um convite à indulgência nos vestibulares, mórmente por parte dos institutos que, para poderem viver, precisam das anuidades de seus alunos.

Crêmos até que, se tomarmos a porcentagem de reprovações, nos exames de ingresso, como índice da seriedade das escolas superiores, não estaremos em nossa apreciação muito longe da justiça. 
A limitação da matrícula constitui, em suma, um preceito legal em pleno vigor, e dos mais sadios e moralizadores da nossa legislação universitária. Mas cumprem tôdas as escolas êsse preceito?

Sabemos perfeitamente que não. Sob o impacto dramático dos resultados de cada exame vestibular, o Diretor se agita, as Congregações vacilam, os Conselhos Universitários capitulam, - Ministro cede, - e a inundação produzida pelo novo dilúvio de estudantes, além de enfraquecer a respeitabilidade da lei, sacrifica o nível e a moralidade do ensino.

Agora, para finalizarmos êste breve confronto entre a lei e a realidade, voltemos ainda uma vez ao instituto da frequência livre, o qual como vimos sob o império da reforma de 1879, esteve a piqué, no dizer de Adolfo Gordo, de aniquilar o ensino superior brasileiro. Contrariando aquela reforma, veio a obrigação de comparecer às aulas, restaurada em 1895 e 1901. Os que acreditavam descobrir na lei da frequência livre o principal fator da dispersão dos estudantes e do estado catastrófico a que chegara, no fim do século passado, o nosso sistema acadêmico, tiveram mais tarde que penitenciar-se. Reconheceu-o Pedro Lessa no Congresso Jurídico de 1908: “depois de regressarmos ao ensino obrigatório (afirmou o insigne mestre, que tanto se batera por isso), continuamos a sentir diàriamente a decadência". De todos os lados se informa que permanecem esquivos às lições os estudantes das Academias. De quem a culpa? indaga Pedro Lessa. "Infelismente, neste particular (responde), não se sabe a quem mais deve ser imputada a falta, se aos alunos ou aos mestres". E' de 1908 o comentário de Pedro Lessa; se, entretanto, o aplicarmos a 1953, ninguém o achará descabido, pois ainda hoje há mestres e discípulos que se acumpliciam a fim de que permaneçam desertas as salas de aulas das faculdades.

Qual o balanço final dêstes entrechoques de reformas e do confronto da realidade escolar com as normas legais do ensino? Mudam as leis, mas os vícios prosseguem. "Abusos ináuditos" - repetiria Ruy Barbosa, — são tolerados e até praticados por 
diretores e professôres; "escândalos tradicionais" - escapam à vigilância das autoridades; "quebras intoleráveis da lei" se perpetuam e legitimam "pela incúria de uns e pelo silêncio de outros".

A eficiência das instituições escolares (insistamos mais uma vez) não depende só das leis: as autoridades e os mestres, os estudantes e os seus pais, o ambiente social e os ideais do tempo, - tudo contribui. Como que por osmose, a sociedade inteira se infiltra através das paredes da escola e a convida a pôr-se em equilíbrio cultural e moral com a tensão exterior. Por isso (já o temos dito), um sistema escolar extenso nunca será nem muito melhor, nem muito pior do que o meio em que funciona.

De outra parte, entretanto, as escolas superiores têm o dever de reagir contra as influências dissolventes, quer endógenas, quer exógenas. Investindo-se na função de reduto dos ideais de cultura e moralidade da Nação, suas corporações docentes não podem pactuar com a pressão malsã que porventura lhes venha do ambiente social, e que tenha a entibiá-las no cumprimento de sua missão ou a rebaixar os seus padrões de conduta. Cabe-lhes, ao contrário, como propulsoras do trabalho espiritual e órgãos da formação do caráter nacional, atuar, não só sôbre os seus discípulos, mas também sôbre o ambiente exterior, no sentido de contrapôr-se às suas fôrças de desagregação e elevá-lo aos níveis em que elas próprias se colocam.

Não me pejo em dizer que a minha conclusão fundamental se reduz a êste simples lugar comum: não podemos confiar sòmente nas reformas, nem supor que elas alcancem, resultados apreciáveis quando lhes falte a boa vontade dos homens. Mais do que isso: entre aperfeiçoar as leis do ensino, e não os homens que as executam, ou inversamente, melhorar os homens deixando as leis como estão, - é esta última, sem dúvida, a reforma preferível. Imagine-se qual não seria o surto de progresso do nosso ensino superior, se de um dia para outro, mediante um passe de mágica, cada um dos seus professôres, de extremo a extremo do País, seguindo o exemplo dos seus cole- 
gas melhores, se decidisse empenhadamente a cumprir os dois deveres fundamentais que lhe impôe a legislação escolar: o de ser bom mestre e o de julgar com critério os seus alunos. Assistir-se-ia com isto, e apenas com isto, a uma grande, generosa e fecunda revolução, capaz de em pouco tempo transformar radicalmente o panorama cultural do País.

Pois basta que êsse passe de mágica se faça, não de um dia para outro, mas através de dois ou três lustros de esfôrço coletivo. Ser bom mestre e ser bom juiz dos alunos: - eis o programa mínimo que bem merece o apôio dêste luzido auditório em que se congregam os principais responsáveis pelo ensino superior brasileiro. Programa que terá execução e terá êxito se cada um dos que aqui se acham emprestar o seu prestígio e a sua autoridade para difundí-lo, defendê-lo e grangear-lhe novos prosélitos. Estamos à véspera, possivelmente, de alterações profundas na organização do ensino superior: alterações que, dilatando a margem de autonomia das corporações escolares, irão solicitar muito mais do que o faz a situação vigente, o espírito de iniciativa e a dedicação do professorado. Se vingar o projeto governamental em curso na Câmara de Deputados, cada escola superior, cada Universidade será em grande parte estruturada pelo seu próprio corpo docente, o qual portanto, nessa fase inicial, terá ensêjo de fornecer a medida de sua cultura e de seu tino pedagógico.

Mas funcionará bem o novo sistema? A resposta depende da consciência cívica e moral do professorado que o integra. Sem esta consciência não há reforma que valha.

Pela segunda vez na história contemporânea da educação superior dêste País, reune-se uma assembléia magna de educadores destinada a traçar a estratégia das batalhas com que os universitários brasileiros esperam vencer os obstáculos antepostos à marcha ascencional do seu ensino. Aos Magníficos Reitores e aos Excelentíssimos Diretores que me honram com a sua atenção, creio haver mostrado que um dêsses obstáculos, - o primeiro dêles, o maior de todos, - tem sido o fraco espírito de cooperação, a culposa indiferença mesmo, que caracteriza a atitude de boa parte do professorado. Foi essa a barreira 
mais alta a prejudicar a trajetória das quatro Academias Imperiais. Foi essa a fôrça que fez nascer, como fez depois cair, a desmoralizada, reforma de Leôncio de Carvalho, e que agravou os malefícios da reforma Rivadávia. Foi essa atitude de apatia que ajudou a dar por terra com o Código Epitácio e que inutilizou a reforma Maximiliano. E' êsse, enfim, em nossos dias, o estôrvo máximo oposto à regularidade na ação didática de numerosos institutos, quer oficiais, quer particulares.

Daí o apêlo que tomo a ousadia de formular e para o qual peço a adesão dos ilustres mestres que me ouvem. Em cada faculdade brasileira organizem-se em núcleo combativo os cumpridores fieis dos deveres funcionais; arregimentem-se nesse núcleo os legionários da assiduidade, os cultores do bom ensino, os paladinos inflexíveis da seriedade nos exames, e, principalmente, os cavaleiros andantes da formação moral da juventude. Logo que isto se alcançar, mais de metade da reforma, - de qualquer reforma, - estará feita.

Bem sei que outros e mais elaborados ideais se apontam como imprescindíveis aos propósitos da Universidade. Mas, se houver no País, de norte a sul, apóstolos inflamados dêsse pequeno evangelho educacional, e se com o apôio prestigioso desta insigne assembléia a iniciativa se converter em norma generalizada de conduta, horizontes mais largos e mais claros hão de abrir-se, amanhã, para o ensino superior brasileiro. 